\title{
Application of Meteorological Element Combination-Driven SWAT Model based on Meteorological Datasets in Alpine catchment: A case study in the Yellow River Source Region (China)
}

\author{
Pengfei $\mathrm{Gu}^{1}$, Yongxiang $\mathrm{Wu}^{2}$, Guodong $\mathrm{Liu}^{1}$, Xia Chengcheng ${ }^{1}$, Gaoxu WANG ${ }^{2}$, Jing Xia ${ }^{1}$, \\ Ke Chen ${ }^{1}$, Xiaohua Huang ${ }^{1}$, and Li Daiyuan ${ }^{2}$ \\ ${ }^{1}$ Sichuan University \\ ${ }^{2}$ Nanjing Hydraulic Research Institute
}

September 21, 2020

\begin{abstract}
Reanalysis meteorological datasets have been widely used for hydrological simulation research in areas where meteorological stations are scarce. However, most of them focus on the applicability of datasets to basin or hydrological model and pay little attention to the influence of meteorological elements of dataset on hydrological modeling. In this study, the precipitation, temperature and solar radiation from three meteorological datasets, gauge dataset (GD), the China Meteorological Assimilation Driving Datasets for the Soil and Water Assessment Tool (SWAT) model (CMADS), and Climate Forecast System Reanalysis (CFSR), were cross-combined with multiple scenarios to drive SWAT models in Yellow River Source Region (YRSR). After a comprehensive comparison of all the scenarios, the main conclusions are as follows: (1) replacing precipitation data has a large impact on streamflow simulation of SWAT model, and using observed precipitation from sparse stations consistently yielded better performance than using precipitation from CMADS and CFSR. (2) In the scenarios adopting observed precipitation as input, using temperature from CMADS and CFSR datasets yielded better performance than using observed temperature. (3) replacing solar radiation has slight impact on the streamflow simulation, and the solar radiation of CFSR is more suitable for hydrological simulation than that of CMADS in YRSR. (4) the SWAT model driven by different meteorological datasets shows that the runoff simulation of GD with CFSR solar radiation data (S6) is optimal with "very good" performance, while the simulation performance of CMADS and CFSR are poor with clearly underestimation for CMADS and significantly overestimation for CFSR, especially in the dry season. These result indicated that the element combination method of the meteorological dataset has been proven to be useful in YRSR, which provides a new insight for hydrological simulation research in areas where meteorological stations are scarce.
\end{abstract}

\section{Introduction}

Hydrological simulation is an important water resources management method (Awange et al., 2019; Bhattarai et al., 2019). Meteorological data are necessary to drive hydrological models, and the spatial and temporal accuracy of data directly affects the model simulation quality (Eini et al., 2019; Wang et al., 2020). Ideally, the meteorological data driving the hydrological model exhibits a reasonable spatial and temporal accuracy and can effectively reflect the weather conditions in the area. Unfortunately, in reality, meteorological stations are sparse and point-based monitoring ranges are limited (Duan et al., 2019), especially in Alpine catchment with complex topographies and harsh climate (Bhatta et al., 2019). The Yellow River Source 
Region (YRSR) is located in the northeast of the Qinghai-Tibet Plateau (Fig. 1) which is also called the "Roof of the World" and "Asian Water Tower" (Tang et al., 2019). It is a typical frigid plateau region and is characterized by high mountains and deep valleys with strong radiation levels, low temperatures, and low oxygen contents. The Yellow River is the mother river of China, and it nurtures $30 \%$ of the Chinese population, irrigates $13 \%$ of arable land in China (Zheng et al., 2009), and plays an important role in Chinese water security. The YRSR is the "water tower" of the Yellow River, and it only accounts for $15 \%$ of the entire basin (Yuan et al., 2018) but contributes $35 \%$ of the water volume in the basin (Hu et al., 2011). Unfortunately, due to the extreme environmental and climatic conditions, the construction and operation costs of meteorological stations are high in YRSR, and the gauge data are scarce. Most available meteorological stations are located at low elevations, which probably leads to an underestimation of measured data, especially in Alpine catchment (Isotta et al., 2014). There are only 12 meteorological stations in the basin, and their distribution is extremely uneven (Fig. 1). The density is far from meeting the requirements of the International Meteorological Organization (WMO, 1994) for gauge station networks (100-250 km² per station for mountainous regions), and it greatly hinders the application of hydrological models (Bhatta et al., 2019). Therefore, it is clear that the YSRS must increase the network density of meteorological stations (financial permitting) or explore other alternative meteorological data sources.

With the development of remote sensing technology, satellite climate products retrieved from remote sensing data provide abundant and valuable observation information and multi-temporal scale meteorological data for hydrological research (Awange et al., 2019; Famiglietti et al., 2015; Schmugge et al., 2002). This provide an opportunity for hydrological model research in catchment with scarce meteorological stations (Famiglietti et al., 2015; Sun et al., 2018). Many scholars have also conducted relevant research using such an approach (Jiang et al., 2012; Worqlul et al., 2017; Xue et al., 2013), but most of these focus on the influence of precipitation meteorological elements on hydrological models (Beck et al., 2017; Fang et al., 2019; Li et al., 2018). However, insufficient literature focus on the influence of temperature and solar radiation meteorological factors on hydrological models in frigid plateau regions with strong radiation levels and low temperatures. The Soil and Water Assessment Tool (SWAT) model has an open source code and is widely used in hydrological model applications (Duan et al., 2019; Eini et al., 2019; Song et al., 2011). The application of the SWAT model in YRSR has also been recognized (Liu et al., 2018). The CFSR dataset recommended by the official SWAT website is highly accurate, sufficiently applicable, user-friendly, and convenient in hydrological model applications. For example, from humid cold to hot semi-arid climate basins in the United States (Hobart, NY; Palm Springs, CA; Santa Fe, NM; and Cross River, NY), the streamflow simulated by CFSR data-driven SWAT models are superior to those driven by gauge data (Fuka et al., 2014). These result has also been demonstrated in the tropical rain forest basin of Puerto Rico (Auerbach et al., 2016). The CFSR dataset can also perform poorly by overestimating the simulation results (Yang et al., 2014). These differences in CFSR dataset performance between different basins and models has attracted the attention of many researchers (Duan et al., 2019; Worqlul et al., 2017). However, these poor performances can be effectively improved by replacing the precipitation meteorological elements. For example, in the upper Gilgel Abay Basin in Ethiopia (Duan et al., 2019), the hydrologic model driven by CFSR data produced unsatisfactory results, but satisfactory results were obtained by replacing the precipitation data. This raises the following question: if other meteorological elements of the dataset are replaced, can the results of the model simulation also be improved? This study aims to answer this research question.

The CMADS dataset developed by Meng et al (2018) for remote areas in China that lack meteorological stations and cannot meet the requirements for large-scale hydrological simulations. The CMADS dataset contains all the meteorological elements required to drive the SWAT model, and it is organized according to the input format of the SWAT model meteorological dataset, which greatly facilitates hydrological and meteorological research. The CMADS dataset has attracted the attention of many researchers due to its high resolution, complete meteorological elements, and calling convenience (Guo et al., 2019; Hao et al., 2019; Xu et al., 2019). The dataset performs well in driving the SWAT model (Guo et al., 2019; Liu et al., 2018). Similarly, the research on the CMADS dataset is predominately concentrated in certain basins and models (Cao et al., 2018; Guo et al., 2019), and there is little research on the various meteorological elements of the 


\section{CMADS dataset.}

In this study, the YRSR, where meteorological stations are scarce, is the research region. The SWAT model is driven under multiple scenarios (Table 4) that cross-combine precipitation (GD, CFSR, and CMADS), temperature (GD, CFSR, and CMADS), and solar radiation (GD and CMADS). The aim is to analyze the performance of meteorological element combination-driven SWAT model based on meteorological datasets, and provide a new insight for hydrological simulation research where meteorological stations are scarce.

\section{Research area}

The YRSR (95 30' E-103deg30' E, 32deg30' N-36deg20' N) is the basin above the Tangnaihai Hydrological Station (C. Gao et al., 2018). The topography of the basin is complex with an altitude of $2675-6253 \mathrm{~m}$ that decreases from the southwest to the northeast (Fig. 1). The YRSR belongs to a typical Qinghai-Tibet Plateau climate (Xu and He, 2006; Yuan et al., 2018), with only cold and warm seasons. The rainfall predominately concentrates in the flood season (June-October), accounting for approximately $75 \%$ of the annual precipitation, and the snowfall is primarily concentrated from September to May (Hu et al., 2011). The mean basin annual precipitation for many years (2008-2012) is approximately $566.96 \mathrm{~mm}$ (Table 3). Rainfall runoff is the predominate runoff pattern in YRSR, accounting for $95.9 \%$ of the total runoff (Liu and Chang, 2005). Base on measured temperature from gauge stations for the period 2008-2012, the annual average daily maximum temperature is 9.53 and minimum temperature is -4.99 (Table 3 ).

Fig. 1 Map of the YRSR

\section{Data and methods}

\subsection{Data}

\subsubsection{Climate data and virtual weather station}

Fig. 1 displays that the meteorological data of 12 weather stations in the basin were derived from the China Meteorological Data Network (http://data.cma.cn/). Because the sparse and uneven distribution of weather stations in the basin, there is only one Maduo station in the northwest of the basin (Fig. 1). Therefore, 2 weather stations (Nuomuhong (NMH) and Qumalai (QML) ) located outside the catchment were selected, which were used as weather stations in the 7 th and 8 th sub-basins (distance: $\mathrm{D}(\mathrm{NMH}-7)<\mathrm{D}(\mathrm{MD}-7)$ ), $\mathrm{D}(\mathrm{QML}-8)<\mathrm{D}(\mathrm{MD}-8))$, respectively.

The CFSR dataset is a global meteorological reanalysis dataset provided by the United States National Environmental Forecasting Center (https://globalweather.tamu.edu/) . It is an interpolation dataset on a $38 \times 38 \mathrm{~km}^{2}$ grid, that integrates surface meteorological gauge data and satellite remote sensing data using assimilation technology and advanced atmospheric, oceanic, and land components (Saha et al., 2014). A total of 122 sites were selected within the research area.

The CMADS dataset is established using the China Meteorological Administration atmospheric assimilation system technology and multiple scientific methods, and cover all of east Asia (0deg N-65deg N, 60deg E160deg E) (Meng et al., 2018). This study adopts version 1.1 of CMADS dataset at a spatial resolution of $25 \mathrm{kmx} 25 \mathrm{~km}$ (http://westdc.westgis.ac.cn/), and a total of 198 sites were selected based on the research area.

Currently, the method of representing weather data in the SWAT model is simplistic, since it only uses data from one weather station that is nearest to the centroid of sub-basin (Galvan et al., 2014). This leads in general to inaccurate representation of sub-basin weather input data, particularly in Alpine catchment with complex topography (Tuo et al., 2016a). In this study, virtual weather stations were constructed for each 
sub-basin that adopts the mean weather element of the site within each sub-basin; all sites data could be utilized to build virtual stations on a sub-basin scale. Detail information on the establishment of Virtual weather station can refer to Ruan et al. (2017)

\subsubsection{Other data}

In addition to meteorological data, the SWAT model requires digital elevation model (DEM), land use, and soil data. The DEM data in this study were derived from SRTM_DEM data with a $90 \mathrm{~m}$ spatial resolution that was provided by the Geospatial Data Cloud (http://www.gscloud.cn/). Land use and soil data (Harmonized World Soil Database version 1.1) with a resolution of $1 \mathrm{~km} \mathrm{x} 1 \mathrm{~km}$ were derived from the Cold and Arid Region Scientific Data Center. To ensure coordinate consistency and spatial data projections, we set the coordinate projection system of the DEM, land use, and soil data to that of WGS 1984_Albers, with a central longitude of 100deg $\mathrm{E}$ and standard latitude (north latitude) of $\varnothing_{1}=33.5 \mathrm{deg}, \bar{\varnothing}_{2}=38 \overline{\mathrm{de}}$.

\subsection{Method}

\subsubsection{SWAT Model}

The SWAT is a semi-distributed, process-based, and time-continuous river basin model (Arnold et al., 1998) that can simulate the basin water cycle process (Duan et al., 2019), soil erosion (Song et al., 2011) and nutrient transportation (Wang et al., 2018; Zhang et al., 2013). We used ArcGIS 10.4 and its corresponding SWAT version to construct SWAT model. In SWAT, the researched basin is divided into various subbasins according to the drainage area threshold, and then further subdivided into Hydrologic Response Units (HRUs) which are composed of land portions with same land use, soil and slope characteristics. Our studied catchment was divided into 25 sub-basins and 1276 HRUs. The HRUs of water balance components, such as precipitation, evapotranspiration, water yield, surface flow, lateral flow, and groundwater flow, were calculated (Neitsch et al., 2011). The water balance equation is as follows:

$\mathrm{SW}_{\mathrm{ti}}=\mathrm{SW}_{\mathrm{oi}}+\sum_{i}^{t}\left(P_{i}-\operatorname{Qsurf}_{i}-E_{i}-\mathrm{Wseep}_{i}-\mathrm{Qgw}_{i}\right)(1)$

Where $\mathrm{SW}_{\mathrm{ti}}$ is the final soil water content $(\mathrm{mm}), \mathrm{SW}_{\mathrm{oi}}$ is the initial soil water content on time $\mathrm{i}(\mathrm{mm}), \mathrm{t}$ is the time (days), $P_{i}$ is the amount of precipitation on time i $(\mathrm{mm})$, Qsurf $_{i}$ is the surface runoff amount on time $\mathrm{i}(\mathrm{mm}), E_{i}$ is the amount of evapotranspiration on time $\mathrm{i}(\mathrm{mm}), \mathrm{Wseep}_{i}$ is the amount of water that enters the vadose zone from the soil profile on time $\mathrm{i}(\mathrm{mm})$, and $\mathrm{Qgw}_{i}$ is the return flow amount on day $\mathrm{i}$ $(\mathrm{mm})$.

The simulation period is 2008-2012, with one-year (2008) warm-up period, two-year (2009-2010) calibration period and two-year (2011-2012) validation period.

\subsubsection{Parameter calibration and model evaluation}

Calibration and uncertainty analysis of the simulation results from the model were performed using the SUFI2 (Sequential Uncertainty Fitting version 2) algorithm in the SWAT- CUP (calibration uncertainty program) software (Abbaspour et al., 2015), because it is highly efficient when used for large basins (Faramarzi et al., 2009; Maringanti et al., 2011). The calibration parameters that greatly influence the model runoff were selected, such as CN2 (Meng et al., 2018; Nerantzaki et al., 2020), and they were combined with the hydrological modeling results for the alpine regions (Bhatta et al.,2019). A total of 18 parameters were selected (Table 1). Runoff data were used for calibration and validation of the SWAT model in runoff simulation. We selected the daily runoff data of Tangnaihai streamflow station, which is located at the YRSR outlet (Fig. 1). According to Abbaspour (2015), three iterations of the calibration procedures were performed with 400 simulations for each iteration (a total of 1200 simulations during calibration). The NashSutcliffe Efficiency (NSE) was used as the evaluation index (Nash and Sutcliffe, 1970). The parameter range of each iteration (except for the first iteration) adopts the parameter range (NEW_PAR) provided by the SWAT-CUP of the last iteration as the initial range of the current iteration (Tuo et al., 2016). In addition 
to NSE, we also used $\mathrm{R}^{2}$ and percent bias (PBIAS) to evaluate the model. The calculation equations, units, ranges, and optimal values of the above evaluation indicators are shown in Table 2. The criteria proposed by D. N. Moriasi et al. (2007) was adopted to classify the performance of model to the respective categories, "very good" (NSE $>0.75$; PBIAS $<+-10 \%)$, "good" $(0.65<$ NSE [?] $0.75 ;+-10 \%$ [?] PBIAS $<+-15 \%)$, "satisfactory" ( $0.50<$ NSE [?] 0.65; +-15\% [?] PBIAS < +-25\%), and "unsatisfactory" (NSE [?] 0.50; PBIAS $[?]+-25 \%)$.

Table 1 Model calibration parameters and initial bound

\subsubsection{Accuracy evaluation method for re-analysis datasets}

To quantitatively evaluate the accuracy of precipitation and temperature from re-analysis datasets, 3 statistical metrics, including the root mean square error (RMSE), percentage bias (PBIAS) and correlation coefficient (CC), were selected at two temporal scales of month and year. The RMSE was used to measure the deviation of the evaluated data compared to that of the gauged data (Eini et al., 2019). The PBIAS denotes the absolute error between the evaluated and gauged data (Yuan et al., 2018). Positive (negative) values indicate that the evaluated data is overestimated (underestimated). The CC exhibited the linear correlation between the evaluated and gauged data (Eini et al., 2019). The detailed information of evaluation indicators can be see Table 2 .

Table 2 Evaluation indicators of reanalysis meteorological dataset and SWAT model

\subsubsection{Technical framework}

There are two main parts of this study. The aim of the first part (precipitation, temperature and solar radiation data evaluation) is to evaluate the applicability of reanalysis-based (CMADS and CFSR) precipitation, temperature and solar radiation data evaluation and then construct the virtual weather station. The second part (streamflow simulation) is that using the meteorological elements of precipitation, temperature and solar radiation were cross-combine drive SWAT models to evaluate the accuracy and application potential in streamflow simulation. In addition, to evaluate the CMADS and CFSR dataset performance for the YRSR, the S19 and S20 scenarios, where the SWAT model is completely driven by the CMADS and CFSR datasets, were utilized. There were 20 scenarios in total (Table 4). The analysis process used in this study is shown in Fig. 2.

Fig. 2 Flow chart of analytical process

\section{Results and discussion}

\subsection{Evaluation of reanalysis meteorological dataset}

Table 3 shows the average values of meteorological elements from multi-stations (i.e. precipitation, maximum temperature, minimum temperature and solar radiation) of GD, CMADS and CFSR at monthly and yearly timescales. According to Table 3, the precipitation, maximum temperature and minimum temperature of CMADS are clearly underestimated on monthly scale, while the precipitation of CFSR is significantly overestimated, and the maximum temperature and minimum temperature of CFSR is obviously underestimated. On the annual scale, compared with gauge data, the deviation of average annual precipitation, maximum temperature and minimum temperature in CMADS is $157.02 \mathrm{~mm}, 3.35$ and 2.38, respectively, and those in CFSR is $226.5 \mathrm{~mm}, 6.03$ and 0.92 , respectively. On the monthly scale, except in March, the solar radiation data of CMADS are higher than those of CFSR, and the average annual solar radiation deviation of CFSR is $598.8 \mathrm{MJ} / \mathrm{m}^{2}$ against with CMADS. Base on Fig. 3, it is obvious that the solar radiation follows a pattern of higher level in the northwest areas and lower level in the Southeast region of YRSR. In addition, in the same region, the annual average total solar radiation of CMADS are obviously higher than CFSR. 
Table 3 The average values of meteorological elements (precipitation, maximum temperature, minimum temperature and solar radiation) from multi-stations at various time scales (monthly and yearly) for different meteorological datasets

Fig. 3 Spatial distributions of annual average total solar radiation from (a) CMADS and (b) CFSR during the January 1, 2008 to December 31, 2012 in YRSR

To further reflect the difference between the precipitation and temperature of reanalysis datasets and the GD, the PBIAS, CC and RMES of the reanalysis datasets and the GD were counted at monthly and yearly timescales. Base on Fig. 4 (a1) and (a2), the deviation of precipitation between reanalysis datasets and GD is generally lower during the wet season (May to November) than during the dry season, and the deviation degree of CFSR is obviously greater than that of CMADS by contrast. The RMSE from reanalysis datasets during the wet season are greater than those from the dry season. The correlation between CFSR and GD is significantly larger than that between CMADS and GD at the monthly scale, and the CMADS is negatively correlated with observed data in most months. As seen in Fig. 4 (b1) and (b2), the maximum temperature of CMADS and CFSR has been underestimated except in January, and the PBIAS value in January is extremely higher compared with other months. The RMSE values of the maximum temperature range from 2.99 to 3.62 for CMDAS and from 3.58 to 8.36 for CFSR at the monthly scale. The minimum temperature of CMADS and CFSR are underestimated at rainy season (May to September), especially in May (Fig. 4 (c1) and (c2)). At the monthly scale, the $\mathrm{CC}$ values of the two datasets varies greatly from month to month in terms of maximum and minimum temperature, and the $\mathrm{CC}$ values in rainy season are larger than those in other months. At the annual scale, the statistical metrics demonstrates that the maximum temperature from CMADS are of higher quality than that from CFSR, while the minimum temperature from CFSR is better than that from CMADS. Overall, the temperature data of the CFSR and CMADS are weakly correlated with the gauge data. The reason for this phenomenon may be due to the fact that most weather stations are located at low altitudes, which cannot effectively reflect the temperature characteristics in YRSR. Li et al. (2003) reported that elevation is a key factor affecting the temperature interpolation algorithm in the Qinghai-Tibet Plateau. Regarding the above analysis, the quality of precipitation and temperature of the CMADS and CFSR in rainy season is obviously higher than that in other months.

Fig. 4 The metrics of multi-station average (a) precipitation, (b) maximum temperature and (c) minimum temperature comparing the gauge data with the (1) CMADS and (2) CFSR at various time scales in YRSR

\subsection{Streamflow simulation results of different meteorological element combina- tion scenarios}

Table 4 summarizes model evaluation statistics for all 20 scenarios at the daily timescales. Fig. 5 displays the simulation results for different input scenarios of meteorological elements (i.e. precipitation, temperature and solar radiation) from the three datasets (GD, CMADS, and CFSR) at the daily timescales. It can be found that the precipitation datasets greatly influence the simulation results of the model, while the datasets of temperature and solar radiation impose slight impact on the streamflow simulation. After a comprehensive comparison of all the scenarios, S4, where the temperature and solar radiation are derived from CFSR dataset, shows the best performance and yielded "very good" performance according to the guideline by (D. N. Moriasi et al., 2007).

Table 4 Summary of the combined scenarios of precipitation, temperature, and solar radiation and simulation results of SWAT model driven by each scenario at the daily scales

Fig. 5 Statistical figures of the simulation results at the daily scale for (a) precipitation, (b) temperature, and (c) solar radiation data input scenarios of the three datasets (GD, CMADS, and CFSR). 


\subsubsection{Streamflow simulation results of different precipitation as input}

According to Fig. 5(a), the average NSE values of the scenarios inputted with the gauge precipitation (S1 S6) in the calibration/validation period are 0.83/0.80, followed by CFSR (S13 S18) at 0.65/0.54, and the worst is CMADS (S7 S12) at 0.18/0.45, indicating that the accuracy of the precipitation data greatly influenced the simulation results, which is one of the reasons why many scholars are committed to studying the impact of precipitation datasets on hydrological models (Eini et al., 2019; Worqlul et al., 2017). Using gauge precipitation (even though with sparse coverage) performed best in daily streamflow simulations for both the calibration ( NSE of $0.79 \sim 0.87$, PBIAS of $-2.3 \% \sim 12.1 \%$ ) and validation (NSE of $0.65 \sim 0.85$ PBIAS of $0.3 \% \sim 48.8 \%$ ) periods. This translates into "good" and "very good" performance according to the guideline by D. N. Moriasi et al. (2007), which may be due to the less human activities in YRSR, so the sparse observation stations for the YRSR can reflect the change of runoff (Mingxing et al., 2018). Scenarios (S13 S18) inputted with CFSR precipitation performed second best in the daily streamflow simulation with obviously overestimation for the calibration (average NSE $=0.65$, PBIAS $=-9.78 \%$ ) and validation (average $\mathrm{NSE}=0.54, \mathrm{PBIAS}=-20.4 \%$ ) periods. In previous studies, scholars reported that the runoff simulation by SWAT model driven by precipitation of CFSR was overestimated (Roth and Lemann, 2016; Worqlul et al., 2017). However, scenarios S14, S16, S17 and S18 yielded satisfactory performance with NES of $0.55 \sim 0.8$ and "very good" performace in terms of S17 and S18 in the calibration periods, while the other scenarios performed poorly (NSE $<0.5)$. Using CMADS precipitation resulted in unsatisfactory performance with NSE of 0.0.9 0.54, and PBIAS of $42 \% \sim 55 \%$, but the NSE in the validation period were very close to 0.50 , the threshold value of being satisfactory, and obviously better than the calibration period.

To further analyze the impact of three different precipitation data on the SWAT model streamflow simulation, we used the control variable method to choose the comparison scenarios. Except for the comparison data, the remainder of the data were derived from the GD, and the solar radiation data of CFSR is adopted uniformly, because the solar radiation data of CFSR are closer to the measured data than those of CMADS (Yan et al., 2019). Therefore, S6 (GD_P + G_T + CF_S), S7 (CM_P + GD_T + CF_S), and S16 $\left(\mathrm{CF} \_\mathrm{P}+\mathrm{GD} \_\mathrm{T}+\mathrm{CF} \_\mathrm{S}\right)$ were selected for comparison. Base on Fig. 6 , the best performance of model with observed precipitation, followed by CFSR and CMADS. The precipitation input into SWAT model by GD, CMADS and CFSR were $519.24 \mathrm{~mm}, 412.51 \mathrm{~mm}$ and $768.07 \mathrm{~mm}$ (Fig. 6(d)), respectively. Among them, the gauge precipitation is the closest to the actual precipitation in YRSR (Hu et al., 2011), explaining the reason why the scenarios of input with gauge precipitation show better simulation result than others (Table 4 and Fig. 5(a)). This finding is consistent with previous studies that point out better performance using measured precipitation or interpolation of measured precipitation than other grided products or re-analysis datasets (Tuo et al., 2016a; Worqlul et al., 2014). S6, the model using gauge precipitation, yielded "very good" performance with NSE of $0.79 \sim 0.80$ and PBIAS of $5.1 \% \sim 8.6 \%$. However, from February to May in each year, the simulation results would be underestimated (Fig. 6(a)), which may be due to the spring runoff recharge of the YRSR was primarily derived from the snowmelt water (Liu et al., 2020), and the snowmelt calculated by the model was small (Fig. 6(d)). Using CMADS precipitation (S12) resulted in "unsatisfactory" simulated daily streamflow with substantial underestimation (PBIAS $=50.6 \% / 46.4 \%$ ) in both calibration and validation periods. More seriously, the simulated streamflow was $0 \mathrm{~m}^{3} / \mathrm{s}$ for a certain period of the dry season (around April every year). This is mainly due to the underestimation in precipitation by CMADS (Table 3 and Fig. 4(a)), and the value of SNOW, PERC and GW_Q calculated by the model were small (Fig. 6(d)). The scenarios (S18) inputted with the CFSR precipitation yielded "very good" performance for the calibration period as good as using gauge precipitation, but the performance was slightly worse for the validation period. This is a good phenomenon, because the CFSR product tended to overestimate precipitation and resulted in "unsatisfactory" runoff simulation using hydrological model (Chen et al., 2018; Hu et al., 2017; Meng et al., 2016; Pomeon et al., 2017; Tan et al., 2018a; Zhu et al., 2016). It can be proved that the performance of hydrological model can be improved by construct virtual weather station and meteorological element combination using CFSR.

Fig. 6 Comparison of daily measured and simulated streamflow from models using three different precipitations (a: GD, b: CMADS, c: CFSR) for the calibration period from 2008-2010 and validation period from 
2011-2012, and (d) output analysis of water balance for models.

Note: PREC means the total precipitation on basin $(\mathrm{mm})$; SNOW means the amount of snow or ice melting $(\mathrm{mm})$; ET means the amount of water removed by evaportranspiration $(\mathrm{mm})$; PERC means the amount of water percolating out of the root zone $(\mathrm{mm})$; SURQ means the surface runoff $(\mathrm{mm})$; GW_Q means the groundwater discharge into reach $(\mathrm{mm})$;WYLD means the net amount of water contributed by the HRU to the reach $\left(\mathrm{mm} \mathrm{H}_{2} \mathrm{O}\right)$; LAT_Q means the lateral flow contribution to reach( $\left.\mathrm{mm}\right)$.

\subsubsection{Streamflow simulation results of different temperature and solar radiation as input}

According to Section 4.2.1, S2 (GD_P + CM_T + CF_S $)$, S4 (CA_P + CF_T + CF_S ) and S6 (GD_P $\left.+\mathrm{GD}_{-} \mathrm{T}+\mathrm{CF} \_\mathrm{S}\right)$ were selected for comparison to analyze the influence of three different temperature data on the simulation results. By combining the results of Fig. 7, the temperature has slighter influence on the model simulation results than precipitation. The average NSE values of the scenarios inputted with the GD, CMADS, and CFSR temperature for the calibration/validation periods are $0.58 / 0.60,0.53 / 0.61$, and 0.54/0.59, respectively (Fig. 5(b)). Base on Fig. 7, scenarios using CFSR temperature as input perform best, followed by those using CMADS and GD. This was inconsistent with previous results that if the same precipitation was used, using gauge and CFSR temperature had almost identical performance (Duan et al., 2019). This is mainly because the temperature of CMADS and CFSR are underestimated (Table 3, Fig. 4(b1), Fig. 4(c1), Fig. 4(b2) and Fig. 4(c2)), resulting in the low evaporation and high streamflow calculated by the SWAT model (Fig. 7(d)). The WYLD values of the scenarios inputted as gauge, CMADS, and CFSR temperature were $149.83 \mathrm{~mm}, 160.64 \mathrm{~mm}$ and $184.44 \mathrm{~mm}$, respectively (Fig. $7(\mathrm{~d})$ ). This shows that the favorable accuracy of CMADS and CFSR temperature to be used for hydrological modelling in YRSR, which is a good news for the local hydrometeorological department as the quality of observed temperature is often worse than that of precipitation (Duan et al., 2019). One existing study by Tan et al. (2017) found that adopting CFSR temperature can yield good streamflow simulation when using SWAT in two basins in Malaysia.

Fig. 7 Comparison of daily measured and simulated streamflow using three different temperature (a: GD, b: CMADS, c: CFSR) for the calibration period from 2008-2010 and validation period from 2011-2012, and (d) output analysis of water balance from models.

Similarly, S5 (GD_P + CA_T + CM_S) and S6 (GD_P + GD_T + CF_S) were selected to evaluate the influence of solar radiation on the daily runoff simulation. According to Fig. 8, we found that the solar radiation has slight influence on the model simulation results in terms of NSE and $R^{2}$. The average NSE values of the scenarios inputted with CMADS and CFSR solar radiation data for the calibration/validation periods are 0.53/0.54 and 0.57/0.65, respectively (Fig. 5(c)). However, the PBIAS values of S5 and S6 are quite different. S6 results in "very good" performance with PBIAS less than 10\%, while S5 yielded "good" performance for the calibration periods $(\mathrm{PBIAS}=12.1 \%)$ and "satisfactory" performance for the validation periods (PBIAS $=20.1 \%$ ). This is primarily because the solar radiation data of the CMADS are greater than those of CFSR (Table 3 and Fig. 3), resulting in large evaporation and small runoff for S5 as calculated by the SWAT model (Fig. 8(c)). This conclusion was verified through the unselected scenarios except the scenarios using CFSR precipitation as inputted in validation periods (Table 4). Regarding to the above analysis, the solar radiation from CFSR is more suitable for hydrological simulation in YRSR than that from CMADS, which is a good news for hydrometeorological model researchers.

Fig. 8 Comparison of daily measured and simulated streamflow using two different solar radiation datasets (a: CMADS and b: CFSR) for the calibration period from 2008-2010 and validation period 2011-2012, and (c) output analysis of water balance from models.

\subsubsection{Streamflow simulation results of different datasets}

To evaluate the applicability of the SWAT model driven by GD (S6), CMADS (S19), and CFSR (S20) for the YRSR, the SWAT model was directly driven without replacing any dataset meteorological elements. 
Apparently, using GD (even though with sparse coverage) as input to driven SWAT were still the one that result in the best daily streamflow simulation in YRSR (Fig.8(b)), followed by CFSR (Fig. 9(b1)) and CMADS (Fig. 9(a1)). The findings of this study are different from those of previous studies, which reported that SWAT model driven by CMADS have a better performance in the research basin (X. Gao et al., 2018; Zhou et al., 2019). Base on Fig. 9 (a1) and (b1), the performance of CMADS and CFSR dataset were poor with clearly underestimation ( PBIAS $\geq 52.3 \%$ ) for CMADS and overestimation (PBIAS $\leq-18 \%$ ) for CFSR, especially in the dry season. Similarly, Yu and Mu (2015) reported that the runoff simulated by SWAT model driven by the CFSR dataset in alpine regions was overestimated, and Wang et al. (2020) found that the runoff simulation result driven by CMADS was severely underestimated. This may because the CMADS (Meng et al., 2018) and CFSR (Radcliffe and Mukundan, 2017; Saha et al., 2014) are generated by interpolation methods based on the observation and satellite remote sensing data, of which the interpolation accuracy is greatly affected by the density of the regional stations and topography (Dodson and Marks, 1997). The elevation of the meteorological stations for the YRSR and surrounding area are lower than the average elevation, and the observatory density is low and uneven (Fig. 1). (Zhang and Tang, 2015) reported that the accuracy of the remote sensing data is poor in this area.

Interestingly, after careful comparison, we found that the simulation result of S19 and S20 could be effectively improved by replacing the meteorological element (Fig. 9 (a2), (a3), (b2) and (b3)), especially for CFSR. S18, the model using CFSR precipitation, gauge temperature and CFSR solar radiation as input, has "very good" performance for the calibration period and "good" performance for the validation period (Fig. 9 (b2)). Similarly, the model of S17 using CFSR precipitation, gauge temperature and CMADS solar radiation as input yielded "very good" performance for the calibration periods and satisfactory performance for the validation periods (Fig. 9 (b3)). Base on Fig. 9 (b4), it is clear that the evaporation of S17 and S18 is greater than that of S20, and the values of SNOW, PERC and GW_Q of S20 are greater than those of S17 and S18, so S20 translated more precipitation into runoff than S17 and S18. This is because the temperature from CFSR is underestimated (Table 3 and Fig. 4), and the solar radiation from CMADS is greater than that from CFSR (Table 3 and Fig. 3), resulting in the large evaporation and small streamflow calculated by the SWAT model. These results indicate that the improvement of hydrological model accuracy is not only helpful in seeking precipitation products with high spatio-temporal accuracy (Guo et al., 2019; Tan et al., 2018b; Yuan et al., 2018) and correcting precipitation data (Deng et al., 2019; Hu et al., 2017; Wang et al., 2020), but also in improving the model accuracy through the combination of meteorological input.

Fig. 9 Comparison of the measured and simulated streamflow daily hydrographs using CMADS (a1, a2 and a3) and CFSR (b1, b2 and b3) precipitation in the calibration period from 2008-2010 and validation period from 2011-2012, and (a4: CMADS, b4: CFSR) output analysis of water balance from models.

\subsection{Discussion with existing studies in the same study area and recommendations for future study}

To date, literature search showed that several studies have been carried out to evaluate the performance of different weather datasets or precipitation datasets in driving hydrological models (particularly SWAT model) to simulate runoff in YRSR. We discussed our results with the most relevant previous studies which considered the same weather datasets (GD, CMADS and CFSR) with our study.

Liu et al. (2018) has been carried out to evaluate the performance of different weather datasets, including GD, CMADS and CFSR, in driving SWAT model in runoff simulation in the same basin. The authors reported that SWAT driven by CMADS and CFSR were better than that driven by GD overall. The evaluation statistics showed that the NSE values of CMADS at the daily scale were 0.63 and 0.59 for calibration periods and validation periods, respectively, while the those of GD were -0.72 and -0.91 . This is completely contrary to our results that GD-driven SWAT has the best result with NSE of $0.79 \sim 0.80$ in YRSR, followed by CFSR with NSE of $0.27 \sim 0.41$ and CMADS with $0.12 \sim 0.39$ (Table 4 ). This could be mainly due to three reasons: (1) Mostly importantly, Liu et al. (2018) used old version of CMADS (1.0) dataset, while our study used CMADS dataset of version 1.1. Although existing studies showed that the new version 
performed better than the old one and had reasonably good agreement with measured runoff, most of them are concentrated on basins in northern China, such as Heihe River Basin (Meng et al., 2019), Manas River Basin (Meng et al., 2017), Jing and Bortala River Basin (Li et al., 2019), Northeast basin (Zhang et al., 2020) and Lijiang River Basin (Cao et al., 2018). In the Jinsha River Basin, Guo et al. (2019) reported that the simulated runoff drived by CMADS only resulted in satisfactory performance with NSE of 0.5 , which is not as good as previous studies (Li et al., 2019; Meng et al., 2019; Zhang et al., 2020). More seriously, in the Xihe River Basin which is located at Qinling Mountains, Wang et al. (2020) found that the monthly streamflow simulation by SWAT driven by CMADS precipitation (1.1) has poorly performance with NSE of -0.43 and PBIAS of $95.22 \%$. These results indicate that the regional heterogeneity of CMADS is significant and that it is necessary to evaluate the accuracy of CMADS before use. (2) Liu et al. (2018) only used 11 meteorological stations in the study area, while our study used 14. Previous study showed that the accuracy of meteorological data directly affects the simulation results of hydrological model (Laiti et al., 2018; Tuo et al., 2016; Wagner et al., 2012). In addition, many scholars (Shuai et al., 2019; Wei et al., 2016) reported that the runoff simulation by SWAT model driven by GD yielded "good" performance in YRSR according to the guideline by D. N. Moriasi et al. (2007), and Yuan et al. (2018) found that using gauge precipitation to drive Xinanjiang model has a slightly better quality than using IMERG (Integrated Multi-satellite Retrievals for Global Precipitation Measurement Mission) Final Run version 05 precipitation products in the same regions. Similarly, in Ethiopia, the data-scare regions of the upper Blue Nile Basin, Duan et al. (2019) and Worqlul et al. (2017) reported that the hydrological model driven by sparse observed precipitation data is better than that driven by high-precision precipitation data. (3) Besides the difference in weather datasets input for SWAT model, the calibration strategies used by Liu et al. (2018) might not be able to find the optimal values for each dataset, although they did not explicitly detail the calibration procedures rather just simply mentioned that 12 sensitive parameters are selected to be calibrated. Our study used more parameters (Table 1) and more objective calibration with the same starting parameter boundary in a sufficient number of iterations, which increases the possibility of finding optimal parameter values for each model.

Snow is an important hydrological reservoir within the water cycle, particularly in alpine catchment, such as Qinghai-Tibet Plateau. As global warming intensifies, the impact of snowmelt on streamflow in frigid plateau regions will be more prominent. Unfortunately, the snowmelt module of SWAT model in YRSR was not ideal as it could not reflect the changes of temperature and solar radiation well (Fig. 7(d) and Fig. 8(d)), and spring runoff was underestimated (Fig. 6(a)). Many literatures reported that snowmelt has great impact on runoff simulation of hydrological model (Abbas et al., 2019; Ficklin and Barnhart, 2014; Kim et al., 2015), especially spring runoff in alpine watershed (Abbas et al., 2019). To date, the metheds to improve the snowmelt runoff of SWAT model include uncertainty evaluation of SWAT model for snowmelt runoff (Abbas et al., 2019; Ficklin and Barnhart, 2014), improvement of SWAT model (Luo et al., 2013) and simulations of snowpack conditions (Pradhanang et al., 2011). Additionally, the scarcity of meteorological stations in alpine basin is common, and it is difficult to improve in a short time. Exploring alternative meteorological datasets which are more feasible, such as satellite meteorological data with high spatial and temporal resolution (Deng et al., 2019; Wang et al., 2020; Yuan et al., 2018), is a good way to improve hydrological model simulation. Therefore, we can optimize hydrological model research for alpine watershed from the above mentioned aspects.

\section{Conclusions}

In this study, the quality of precipitation, temperature, and solar radiation data of the CMADS and CFSR datasets over the YRSR were first evaluated. Then, the three meteorological elements of precipitation, temperature and solar radiation were combined. A total of 20 scenarios were used to drive the SWAT model, and the applicability of each scenario in YRSR was evaluated. The main research conclusions are as follows.

(1) In YRSR, compared with GD, the precipitation, maximum temperature and minimum temperature of CFSR are overestimated, underestimated and underestimated, respectively, while those of CMADS are all 
underestimated. And the quality of precipitation and temperature of the CMADS and CFSR in rainy season is obviously higher than that in other months.

(2) Replacing precipitation data has a large impact on streamflow simulation results of hydrological models. Using gauge precipitation from sparse stations consistently yielded better performance in runoff simulation than using precipitation from CMADS and CFSR. The average NSE values of the scenarios inputted with the gauge precipitation $(\mathrm{S} 1 \sim \mathrm{S} 6)$ in the calibration/validation period is $0.83 / 0.80$, followed by CFSR (S13 S18) at $0.65 / 0.54$, and the worst is CMADS $(\mathrm{S} 7 \sim \mathrm{S} 12)$ at $0.18 / 0.45$.

(3) Replacing temperature has slight influence on the model simulation results than replacing the precipitation. The average NSE values of the scenarios inputted with the GD, CMADS, and CFSR temperature for the calibration/validation periods are $0.58 / 0.60,0.53 / 0.61$, and $0.54 / 0.59$, respectively. In the scenarios with observed precipitation as input, using CMADS and CFSR temperature yielded better performance than using observed temperature. This shows that the favorable accuracy of temperature from CMADS and CFSR to be used for hydrological modelling in YRSR, which is a good news for the local hydrometeorological department as the quality of observed temperature is often worse that of precipitation.

(4) Replacing solar radiation has slight impact on the streamflow simulation. The average NSE values of the scenarios inputted with CMADS and CFSR solar radiation data for the calibration/validation periods are $0.53 / 0.54$ and $0.57 / 0.65$, respectively. By contrast, the solar radiation of CFSR is more suitable for hydrological simulation in YRSR than CMADS.

(5) The SWAT model driven by different meteorological datasets showed that the runoff simulation of GD with CFSR solar radiation data (S6) is optimal with "very good" performance (NSE $\geq 0.79,5.1 \% \leq \mathrm{PBIAS} \leq$ $8.6 \%$ ), while the simulation performance of CMADS and CFSR dataset are poor with clearly underestimation ( PBIAS $\geq 52.3 \%$ ) for CMADS and overestimation (PBIAS $\leq-18 \%$ ) for CFSR, especially in the dry season.

In summary, in YRSR, using gauge data from sparse stations consistently yielded better performance in runoff simulation by SWAT model than using CMADS and CFSR. Replacing the meteorological elements of the meteorological datasets has a certain influence on the simulation results, especially the precipitation element. These results indicated that the element combination method of the meteorological dataset has been proven to be useful in YRSR, which provides a new insight for hydrological simulation research in areas where meteorological stations are scarce.

\section{Acknowledgements}

This work was supported by National Key Research and Development Program of China (grant numbers: 2016YFC0401005, 2016YFA0601703) and Nation Nature Science Foundation of China (grant numbers: 91847301). Acknowledgement for the data support form "National Earth System Science Data Center, National Science \& Technology Infrastructure of Chia. (http://www.geodata.cn)"

\section{References}

Abbas, T., Hussain, F., Nabi, G., Boota, M.W., Wu, R.S., 2019. Uncertainty evaluation of SWAT model for snowmelt runoff in a Himalayan watershed. Terr. Atmos. Ocean. Sci. 30, 265-279. https://doi.org/10.3319/TAO.2018.10.08.01

Abbaspour, K., 2015. SWAT-Calibration and uncertainty programs (CUP). Neprashtechnology.Ca. https://doi.org/10.1007/s00402-009-1032-4

Arnold, J.G., Srinivasan, R., Muttiah, R.S., Williams, J.R., 1998. Large area hydrologic modeling and assessment part I: Model development. J. Am. Water Resour. Assoc. https://doi.org/10.1111/j.17521688.1998.tb05961.x 
Auerbach, D.A., Easton, Z.M., Walter, M.T., Flecker, A.S., Fuka, D.R., 2016. Evaluating weather observations and the Climate Forecast System Reanalysis as inputs for hydrologic modelling in the tropics. Hydrol. Process. https://doi.org/10.1002/hyp.10860

Awange, J.L., Hu, K.X., Khaki, M., 2019. The newly merged satellite remotely sensed, gauge and reanalysisbased Multi-Source Weighted-Ensemble Precipitation: Evaluation over Australia and Africa (1981-2016). Sci. Total Environ. https://doi.org/10.1016/j.scitotenv.2019.03.148

Beck, H.E., Vergopolan, N., Pan, M., Levizzani, V., Van Dijk, A.I.J.M., Weedon, G.P., Brocca, L., Pappenberger, F., Huffman, G.J., Wood, E.F., 2017. Global-scale evaluation of 22 precipitation datasets using gauge observations and hydrological modeling. Hydrol. Earth Syst. Sci. https://doi.org/10.5194/hess-216201-2017

Bhatta, B., Shrestha, S., Shrestha, P.K., Talchabhadel, R., 2019. Evaluation and application of a SWAT model to assess the climate change impact on the hydrology of the Himalayan River Basin. Catena. https://doi.org/10.1016/j.catena.2019.104082

Bhattarai, N., Mallick, K., Stuart, J., Vishwakarma, B.D., Niraula, R., Sen, S., Jain, M., 2019. An automated multi-model evapotranspiration mapping framework using remotely sensed and reanalysis data. Remote Sens. Environ. https://doi.org/10.1016/j.rse.2019.04.026

Cao, Y., Zhang, J., Yang, M., Lei, X., Guo, B., Yang, L., Zeng, Z., Qu, J., 2018. Application of SWAT model with CMADS data to estimate hydrological elements and parameter uncertainty based on SUFI-2 algorithm in the Lijiang River basin, China. Water (Switzerland). https://doi.org/10.3390/w10060742

Chen, A., Chen, D., Azorin-Molina, C., 2018. Assessing reliability of precipitation data over the Mekong River Basin: A comparison of ground-based, satellite, and reanalysis datasets. Int. J. Climatol. https://doi.org/10.1002/joc.5670

D. N. Moriasi, J. G. Arnold, M. W. Van Liew, R. L. Bingner, R. D. Harmel, T. L. Veith, 2007. Model Evaluation Guidelines for Systematic Quantification of Accuracy in Watershed Simulations. Trans. ASABE. https://doi.org/10.13031/2013.23153

Deng, P., Zhang, M., Bing, J., Jia, J., Zhang, D., 2019. Evaluation of the GSMaP_Gauge products using rain gauge observations and SWAT model in the Upper Hanjiang River Basin. Atmos. Res. 219, 153-165. https://doi.org/10.1016/j.atmosres.2018.12.032

Dodson, R., Marks, D., 1997. Daily air temperature interpolated at high spatial resolution over a large mountainous region. Clim. Res. https://doi.org/10.3354/cr008001

Duan, Z., Tuo, Y., Liu, J., Gao, H., Song, X., Zhang, Z., Yang, L., Mekonnen, D.F., 2019. Hydrological evaluation of open-access precipitation and air temperature datasets using SWAT in a poorly gauged basin in Ethiopia. J. Hydrol. 569, 612-626. https://doi.org/10.1016/j.jhydrol.2018.12.026

Eini, M.R., Javadi, S., Delavar, M., Monteiro, J.A.F., Darand, M., 2019. High accuracy of precipitation reanalyses resulted in good river discharge simulations in a semi-arid basin. Ecol. Eng. https://doi.org/10.1016/j.ecoleng.2019.03.005

Famiglietti, J.S., Cazenave, A., Eicker, A., Reager, J.T., Rodell, M., Velicogna, I., 2015. Satellites provide the big picture. Science (80-. ). https://doi.org/10.1126/science.aac9238

Fang, J., Yang, W., Luan, Y., Du, J., Lin, A., Zhao, L., 2019. Evaluation of the TRMM 3B42 and GPM IMERG products for extreme precipitation analysis over China. Atmos. Res. https://doi.org/10.1016/j.atmosres.2019.03.001

Faramarzi, M., Abbaspour, K.C., Schulin, R., Yang, H., 2009. Modelling blue and green water resources availability in Iran. Hydrol. Process. https://doi.org/10.1002/hyp.7160 
Ficklin, D.L., Barnhart, B.L., 2014. SWAT hydrologic model parameter uncertainty and its implications for hydroclimatic projections in snowmelt-dependent watersheds. J. Hydrol. 519, 2081-2090. https://doi.org/10.1016/j.jhydrol.2014.09.082

Fuka, D.R., Walter, M.T., Macalister, C., Degaetano, A.T., Steenhuis, T.S., Easton, Z.M., 2014. Using the Climate Forecast System Reanalysis as weather input data for watershed models. Hydrol. Process. https://doi.org/10.1002/hyp.10073

Galvan, L., Olias, M., Izquierdo, T., Ceron, J.C., Fernandez de Villaran, R., 2014. Rainfall estimation in SWAT: An alternative method to simulate orographic precipitation. J. Hydrol. 509, 257-265. https://doi.org/10.1016/j.jhydrol.2013.11.044

Gao, C., Liu, L., Wang, Z., Xu, Y., 2018. Precipitation bias-correction methods for Yellow River basin upstream of Tangnaihai. Shuili Fadian Xuebao/Journal Hydroelectr. Eng. 37, 29-39. https://doi.org/10.11660/slfdxb.20180904 (in Chinese)

Gao, X., Zhu, Q., Yang, Z., Wang, H., 2018. Evaluation and hydrological application of CMADS against TRMM 3B42V7, PERSIANN-CDR, NCEP-CFSR, and gauge-based datasets in Xiang River basin of China. Water (Switzerland). https://doi.org/10.3390/w10091225

Guo, D., Wang, H., Zhang, X., Liu, G., 2019. Evaluation and analysis of grid precipitation fusion products in Jinsha river basin based on China meteorological assimilation datasets for the SWAT model. Water (Switzerland). https://doi.org/10.3390/w11020253

Hao, Y., Baik, J., Choi, M., 2019. Combining generalized complementary relationship models with the Bayesian Model Averaging method to estimate actual evapotranspiration over China. Agric. For. Meteorol. https://doi.org/10.1016/j.agrformet.2019.107759

Hu, S., Qiu, H., Yang, D., Cao, M., Song, J., Wu, J., Huang, C., Gao, Y., 2017. Evaluation of the applicability of climate forecast system reanalysis weather data for hydrologic simulation: A case study in the Bahe River Basin of the Qinling Mountains, China. J. Geogr. Sci. https://doi.org/10.1007/s11442-017-1392-6

Hu, Y., Maskey, S., Uhlenbrook, S., Zhao, H., 2011. Streamflow trends and climate linkages in the source region of the Yellow River, China. Hydrol. Process. https://doi.org/10.1002/hyp.8069

Isotta, F.A., Frei, C., Weilguni, V., Perčec Tadić, M., Lassègues, P., Rudolf, B., Pavan, V., Cacciamani, C., Antolini, G., Ratto, S.M., Munari, M., Micheletti, S., Bonati, V., Lussana, C., Ronchi, C., Panettieri, E., Marigo, G., Vertačnik, G., 2014. The climate of daily precipitation in the Alps: Development and analysis of a high-resolution grid dataset from pan-Alpine rain-gauge data. Int. J. Climatol. https://doi.org/10.1002/joc.3794

Jiang, S., Ren, L., Hong, Y., Yong, B., Yang, X., Yuan, F., Ma, M., 2012. Comprehensive evaluation of multi-satellite precipitation products with a dense rain gauge network and optimally merging their simulated hydrological flows using the Bayesian model averaging method. J. Hydrol. https://doi.org/10.1016/j.jhydrol.2012.05.055

Kim, S.B., Shin, H.J., Park, M., Kim, S.J., 2015. Assessment of future climate change impacts on snowmelt and stream water quality for a mountainous high-elevation watershed using SWAT. Paddy Water Environ. 13, 557-569. https://doi.org/10.1007/s10333-014-0471-x

Laiti, L., Mallucci, S., Piccolroaz, S., Bellin, A., Zardi, D., Fiori, A., Nikulin, G., Majone, B., 2018. Testing the Hydrological Coherence of High-Resolution Gridded Precipitation and Temperature Data Sets. Water Resour. Res. https://doi.org/10.1002/2017WR021633

Li, D., Christakos, G., Ding, X., Wu, J., 2018. Adequacy of TRMM satellite rainfall data in driving the SWAT modeling of Tiaoxi catchment (Taihu lake basin, China). J. Hydrol. https://doi.org/10.1016/j.jhydrol.2017.01.006 
Li, X., Chen, G., Lu, L., 2003. Comparison Study of Spatial Interpolation Methods of Air Temperature over Qinghai-Xizang Plateau. Plateau Meteorol. 22, 565-573. https://doi.org/1000-0534(2003)06-0565-09

Li, Y., Wang, Y., Zheng, J., Yang, M., 2019. Investigating spatial and temporal variation of hydrological processes in western China driven by CMADS. Water (Switzerland) 11. https://doi.org/10.3390/w11030435

Liu, J., Shanguan, D., Liu, S., Ding, Y., 2018. Evaluation and hydrological simulation of CMADS and CFSR reanalysis datasets in the Qinghai-Tibet Plateau. Water (Switzerland). https://doi.org/10.3390/w10040513

Liu, X., Chang, X., 2005. A Summary of Study on RunoffVar iations in Source Reg ion of the Yellow R iver. YELLOW RIVER 27, 6-12. https://doi.org/1000 - 1379(2005)02 - 0006 -03 (in Chinese)

Liu, X., Chen, R., Liu, J., Wang, X., Zhang, B., Liu, G., 2020. Variation of Snow Cover and its Influence on Spring Runoff in the Source Region of Yellow River. Plateau Meteorol. 39, 226-233. https://doi.org/10. 7522/j. issn. 1000-0534. 2019. 00074 (in Chinese)

Luo, Y., Arnold, J., Liu, S., Wang, X., Chen, X., 2013. Inclusion of glacier processes for distributed hydrological modeling at basin scale with application to a watershed in Tianshan Mountains, northwest China. J. Hydrol. 477, 72-85. https://doi.org/10.1016/j.jhydrol.2012.11.005

Maringanti, C., Chaubey, I., Arabi, M., Engel, B., 2011. Application of a multi-objective optimization method to provide least cost alternatives for NPS pollution control. Environ. Manage. https://doi.org/10.1007/s00267-011-9696-2

Meng, X., Shi, C., Liu, S., Wang, H., Lei, X., Liu, Z., Ji, X., Cai, S., Zhao, Q., 2016. CMADS Datasets and Its Application in Watershed Hydrological Simulation: A Case Study of the Heihe River Basin. Pearl River 37, 1-19. (in Chinese) https://doi.org/10.3969/j.issn.1001-9235.2016.07.001

Meng, X., Wang, H., Lei, X., Cai, S., Wu, H., Ji, X., Wang, J., 2017. Hidrološko modeliranje u porječju rijeke Manas primjenom alata za procjenu tla i vode pomoću CMADS-a. Teh. Vjesn. 24, 525-534. https://doi.org/10.17559/TV-20170108133334

Meng, X., Wang, H., Shi, C., Wu, Y., Ji, X., 2018. Establishment and evaluation of the China meteorological assimilation driving datasets for the SWAT model (CMADS). Water (Switzerland). https://doi.org/10.3390/w10111555

Meng, X., Zhang, X., Yang, M., Wang, H., Chen, J., Pan, Z., Wu, Y., 2019. Application and evaluation of the China Meteorological Assimilation Driving Datasets For The Swat Model (CMADS) in poorly gauged regions in Western China. Water (Switzerland) 11, 1-28. https://doi.org/10.3390/w11102171

Mingxing, S., Yongchao, L., Yongping, S., Hui, T., Xin, W., Chengfang, L., Huying, M., 2018. Analyses of multiple time scales characteristics and mutation of pan evaporation variation in the source regions of the Yellow River from 1961 to 2014. J. Glaciol. Geocryol. 40, 666-675. https://doi.org/10.7522/j.issn.10000240.2018 .0072

Neitsch, S.., Arnold, J.., Kiniry, J.., Williams, J.., 2011. Soil \& Water Assessment Tool Theoretical Documentation Version 2009. Texas Water Resour. Inst. https://doi.org/10.1016/j.scitotenv.2015.11.063

Nerantzaki, S.D., Hristopulos, D.T., Nikolaidis, N.P., 2020. Estimation of the uncertainty of hydrologic predictions in a karstic Mediterranean watershed. Sci. Total Environ. https://doi.org/10.1016/j.scitotenv.2020.137131

Poméon, T., Jackisch, D., Diekkrüger, B., 2017. Evaluating the performance of remotely sensed and reanalysed precipitation data over West Africa using HBV light. J. Hydrol. https://doi.org/10.1016/j.jhydrol.2017.01.055

Pradhanang, S.M., Anandhi, A., Mukundan, R., Zion, M.S., Pierson, D.C., Schneiderman, E.M., Matonse, A., Frei, A., 2011. Application of SWAT model to assess snowpack development and streamflow in the Cannonsville watershed, New York, USA. Hydrol. Process. https://doi.org/10.1002/hyp.8171 
Radcliffe, D.E., Mukundan, R., 2017. PRISM vs. CFSR Precipitation Data Effects on Calibration and Validation of SWAT Models. J. Am. Water Resour. Assoc. https://doi.org/10.1111/1752-1688.12484

Roth, V., Lemann, T., 2016. Comparing CFSR and conventional weather data for discharge and soil loss modelling with SWAT in small catchments in the Ethiopian Highlands. Hydrol. Earth Syst. Sci. https://doi.org/10.5194/hess-20-921-2016

Ruan, H., Zou, S., Yang, D., Wang, Y., Yin, Z., Lu, Z., Li, F., Xu, B., 2017. Runoff simulation by SWAT model using high-resolution gridded precipitation in the upper Heihe River Basin, Northeastern Tibetan Plateau. Water (Switzerland) 9, 1-23. https://doi.org/10.3390/w9110866

Saha, S., Moorthi, S., Wu, X., Wang, J., Nadiga, S., Tripp, P., Behringer, D., Hou, Y.T., Chuang, H.Y., Iredell, M., Ek, M., Meng, J., Yang, R., Mendez, M.P., Van Den Dool, H., Zhang, Q., Wang, W., Chen, M., Becker, E., 2014. The NCEP climate forecast system version 2. J. Clim. https://doi.org/10.1175/JCLI-D$12-00823.1$

Schmugge, T.J., Kustas, W.P., Ritchie, J.C., Jackson, T.J., Rango, A., 2002. Remote sensing in hydrology. Adv. Water Resour. https://doi.org/10.1016/S0309-1708(02)00065-9

Shuai, Z., Yimin, W., Aijun, G., Kai, Z., Ziyan, L., 2019. Influence of uncertainties in SWAT model parameters on runoff simulation in upper reaches of the Yellow River. J. Northwest A\&F Univ. (Nat. Sci. Ed) 47, 144-154. https://doi.org/10.13207/j.cnki.jnwafu.2019.08.018

Song, X., Duan, Z., Kono, Y., Wang, M., 2011. Integration of remotely sensed C factor into SWAT for modelling sediment yield. Hydrol. Process. https://doi.org/10.1002/hyp.8066

Sun, R., Yuan, H., Yang, Y., 2018. Using multiple satellite-gauge merged precipitation products ensemble for hydrologic uncertainty analysis over the Huaihe River basin. J. Hydrol. https://doi.org/10.1016/j.jhydrol.2018.09.024

Tan, M.L., Chua, V.P., Tan, K.C., Brindha, K., 2018a. Evaluation of TMPA 3B43 and NCEPCFSR precipitation products in drought monitoring over Singapore. Int. J. Remote Sens. https://doi.org/10.1080/01431161.2018.1425566

Tan, M.L., Gassman, P.W., Cracknell, A.P., 2017. Assessment of three long-term gridded climate products for hydro-climatic simulations in tropical river basins. Water (Switzerland). https://doi.org/10.3390/w9030229

Tan, M.L., Samat, N., Chan, N.W., Roy, R., 2018b. Hydro-meteorological assessment of three GPM Satellite Precipitation Products in the Kelantan River Basin, Malaysia. Remote Sens. https://doi.org/10.3390/rs10071011

Tang, Q., Lan, C., Su, F., Liu, Xingcai, Sun, H., Ding, J., Wang, L., Leng, G., Zhang, Y., Sang, Y., Fang, H., Zhang, S., Han, D., Liu, Xiaomang, He, L., Xu, X., Tang, Y., Chen, D., 2019. Streamflow change on the Qinghai-Tibet Plateau and its impacts. Kexue Tongbao/Chinese Sci. Bull. 64, 2807-2821. (in Chinese) https://doi.org/10.1360/TB-2019-0141

Tuo, Y., Duan, Z., Disse, M., Chiogna, G., 2016a. Evaluation of precipitation input for SWAT modeling in Alpine catchment: A case study in the Adige river basin (Italy). Sci. Total Environ. 573, 66-82. https://doi.org/10.1016/j.scitotenv.2016.08.034

Tuo, Y., Duan, Z., Disse, M., Chiogna, G., 2016b. Evaluation of precipitation input for SWAT modeling in Alpine catchment: A case study in the Adige river basin (Italy). Sci. Total Environ. https://doi.org/10.1016/j.scitotenv.2016.08.034

Wagner, P.D., Fiener, P., Wilken, F., Kumar, S., Schneider, K., 2012. Comparison and evaluation of spatial interpolation schemes for daily rainfall in data scarce regions. J. Hydrol. https://doi.org/10.1016/j.jhydrol.2012.07.026 
Wang, N., Liu, Wenbin, Sun, F., Yao, Z., Wang, H., Liu, Wanqing, 2020. Evaluating satellite-based and reanalysis precipitation datasets with gauge-observed data and hydrological modeling in the Xihe River Basin, China. Atmos. Res. https://doi.org/10.1016/j.atmosres.2019.104746

Wang, Q., Liu, R., Men, C., Guo, L., 2018. Application of genetic algorithm to land use optimization for non-point source pollution control based on CLUE-S and SWAT. J. Hydrol. https://doi.org/10.1016/j.jhydrol.2018.03.022

Wei, J., Chang, J., Chen, L., 2016. Runoff change in upper reach of Yellow River under future climate change based on VIC model. Shuili Fadian Xuebao/Journal Hydroelectr. Eng. 35, 65-74. https://doi.org/10.11660/slfdxb.20160508 (in Chinese)

Worqlul, A.W., Maathuis, B., Adem, A.A., Demissie, S.S., Langan, S., Steenhuis, T.S., 2014. Comparison of rainfall estimations by TRMM 3B42, MPEG and CFSR with ground-observed data for the Lake Tana basin in Ethiopia. Hydrol. Earth Syst. Sci. https://doi.org/10.5194/hess-18-4871-2014

Worqlul, A.W., Yen, H., Collick, A.S., Tilahun, S.A., Langan, S., Steenhuis, T.S., 2017. Evaluation of CFSR, TMPA 3B42 and ground-based rainfall data as input for hydrological models, in data-scarce regions: The upper Blue Nile Basin, Ethiopia. Catena. https://doi.org/10.1016/j.catena.2017.01.019

Xu, X., Gao, P., Zhu, X., Guo, W., Ding, J., Li, C., Zhu, M., Wu, X., 2019. Design of an integrated climatic assessment indicator (ICAI) for wheat production: A case study in Jiangsu Province, China. Ecol. Indic. https://doi.org/10.1016/j.ecolind.2019.01.059

Xu, Z., He, W., 2006. Spatial and Temporal Characteristics and Change Trend of Climatic Elements in the Headwater Region of the Yellow River in Recent 40 Years. PLATEAU METEORO LOGY 25, 906-913. https://doi.org/1000-0534(2006)05-0906-08 (in Chinese)

Xue, X., Hong, Y., Limaye, A.S., Gourley, J.J., Huffman, G.J., Khan, S.I., Dorji, C., Chen, S., 2013. Statistical and hydrological evaluation of TRMM-based Multi-satellite Precipitation Analysis over the Wangchu Basin of Bhutan: Are the latest satellite precipitation products 3B42V7 ready for use in ungauged basins? J. Hydrol. https://doi.org/10.1016/j.jhydrol.2013.06.042

Yan, X., Jun, W., Rong, L., Xin, W., Dongyu, J., 2019. An initial analysis of characteristics of radiation budget near ground in alpine wetland in source area of the Yellow River. Acta Energiae Solaris Sin. 40, 1-10.

Yang, Y., Wang, G., Wang, L., Yu, J., Xu, Z., 2014. Evaluation of gridded precipitation data for driving SWAT model in area upstream of three gorges reservoir. PLoS One. https://doi.org/10.1371/journal.pone.0112725

Yu, Y., Mu, Z., 2015. Applicability of CFSR Data in Runoff Simulation of Cold Highland Area. J. Irrig. Drain. 34, 93-97. https://doi.org/1672-3317(2015)11-0093-05

Yuan, F., Wang, B., Shi, C., Cui, W., Zhao, C., Liu, Y., Ren, L., Zhang, L., Zhu, Y., Chen, T., Jiang, S., Yang, X., 2018. Evaluation of hydrological utility of IMERG Final run V05 and TMPA 3B42V7 satellite precipitation products in the Yellow River source region, China. J. Hydrol. https://doi.org/10.1016/j.jhydrol.2018.06.045

Zhang, L., Meng, X., Wang, H., Yang, M., Cai, S., 2020. Investigate the applicability of CMADS and CFSR reanalysis in Northeast China. Water (Switzerland). https://doi.org/10.3390/W12040996

Zhang, P., Liu, Y., Pan, Y., Yu, Z., 2013. Land use pattern optimization based on CLUE-S and SWAT models for agricultural non-point source pollution control. Math. Comput. Model. https://doi.org/10.1016/j.mcm.2011.10.061

Zhang, X., Tang, Q., 2015. Combining satellite precipitation and long-term ground observations for hydrological monitoring in China. J. Geophys. Res. https://doi.org/10.1002/2015JD023400 
Zheng, H., Zhang, L., Zhu, R., Liu, C., Sato, Y., Fukushima, Y., 2009. Responses of streamflow to climate and land surface change in the headwaters of the Yellow River Basin. Water Resour. Res. https://doi.org/10.1029/2007WR006665

Zhou, Z., Gao, X., Yang, Z., Feng, J., Meng, C., Xu, Z., 2019. Evaluation of hydrological application of CMADS in Jinhua River Basin, China. Water (Switzerland). https://doi.org/10.3390/w11010138

Zhu, Q., Xuan, W., Liu, L., Xu, Y.P., 2016. Evaluation and hydrological application of precipitation estimates derived from PERSIANN-CDR, TRMM 3B42V7, and NCEP-CFSR over humid regions in China. Hydrol. Process. https://doi.org/10.1002/hyp.10846
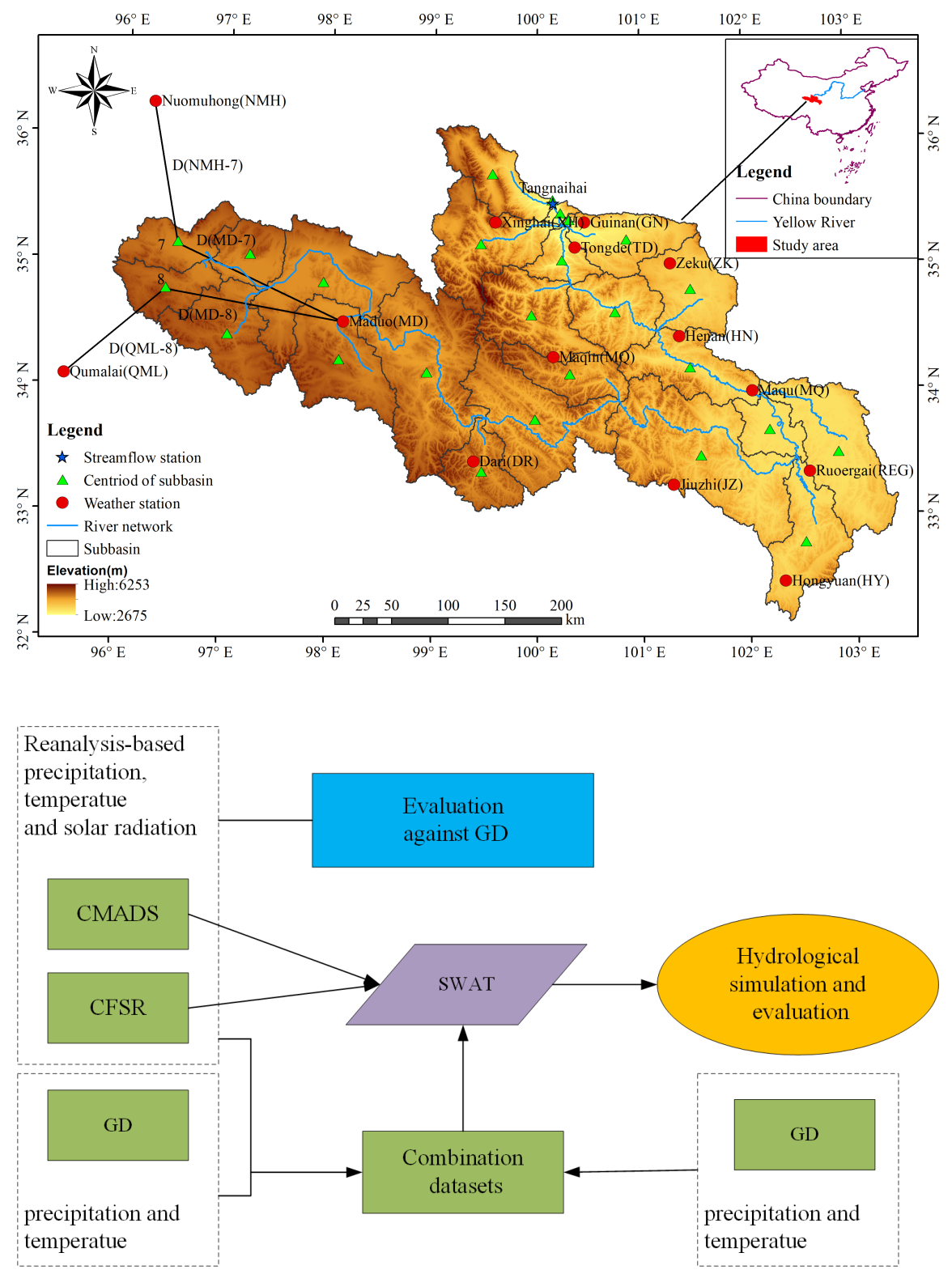

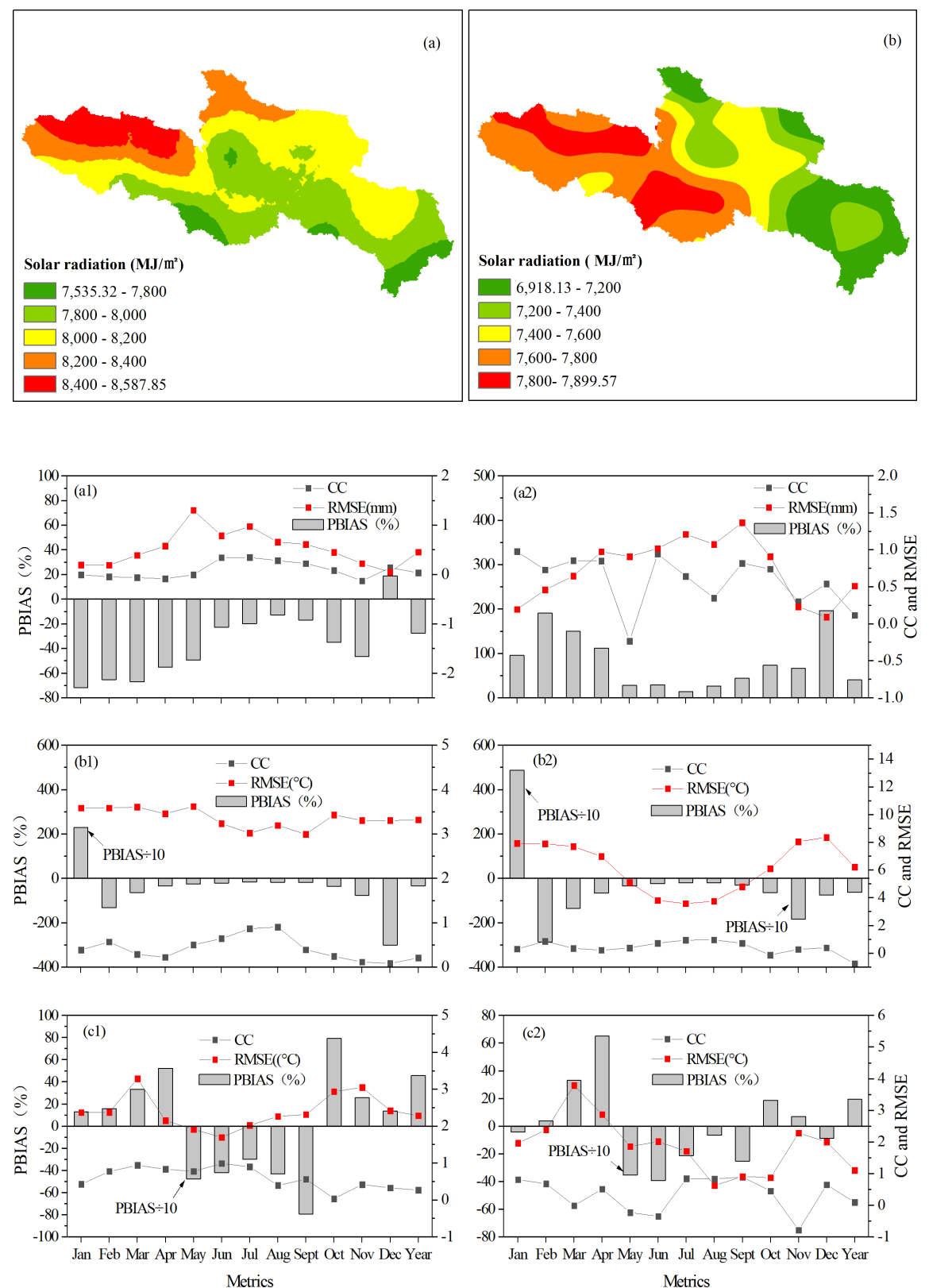
(a) precipitation
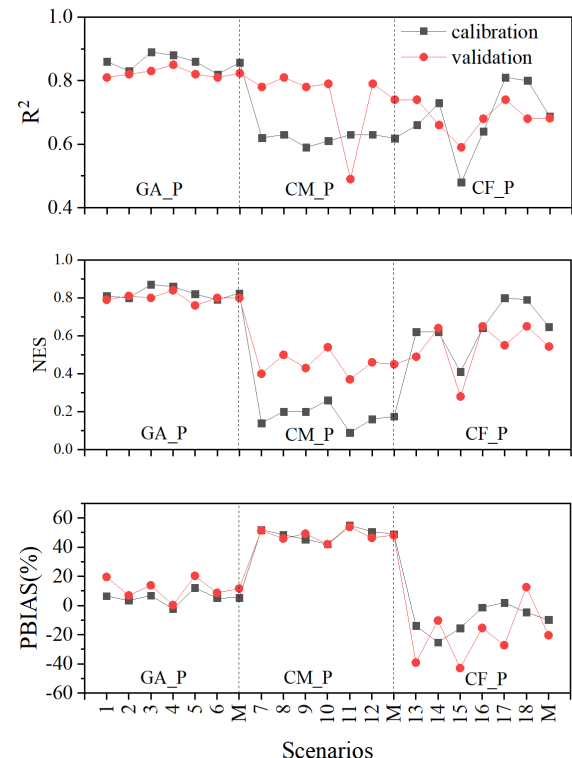

(b) temperature
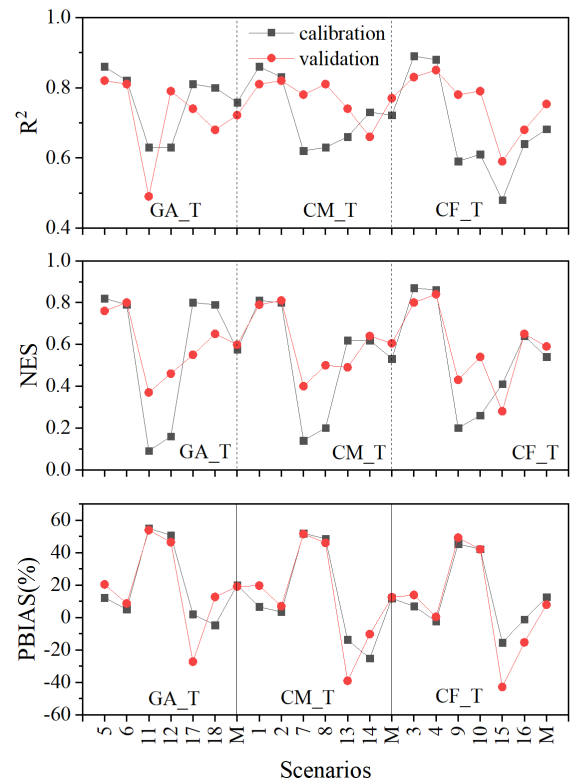

(c) solar radiation
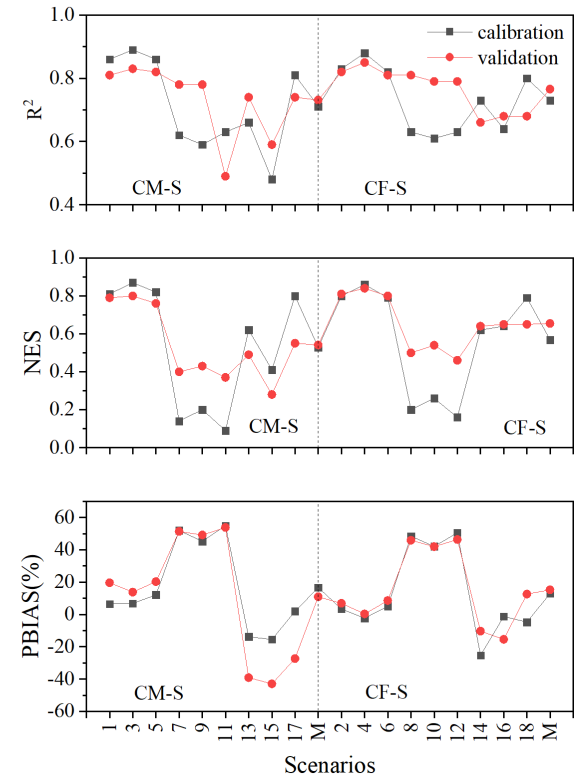

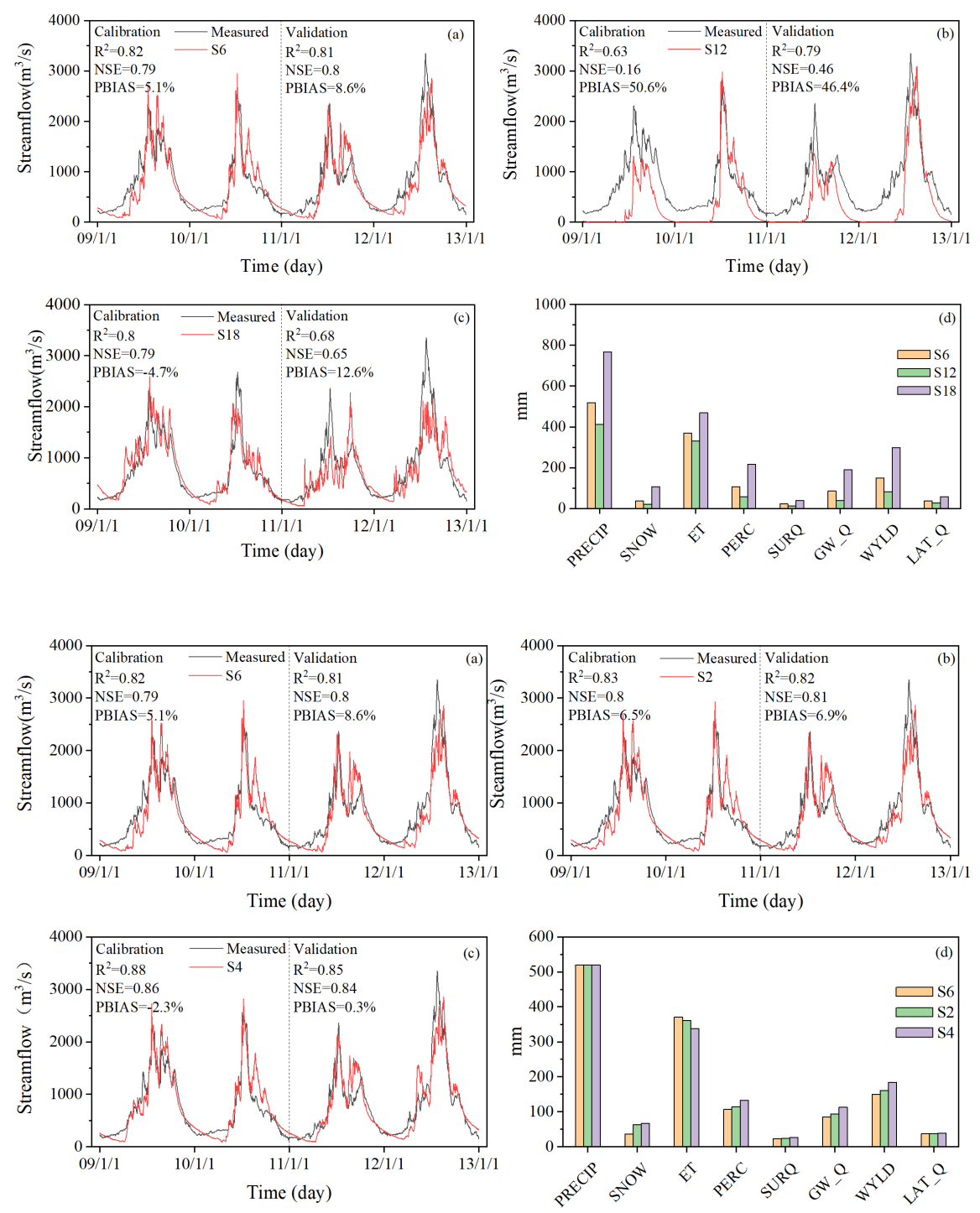

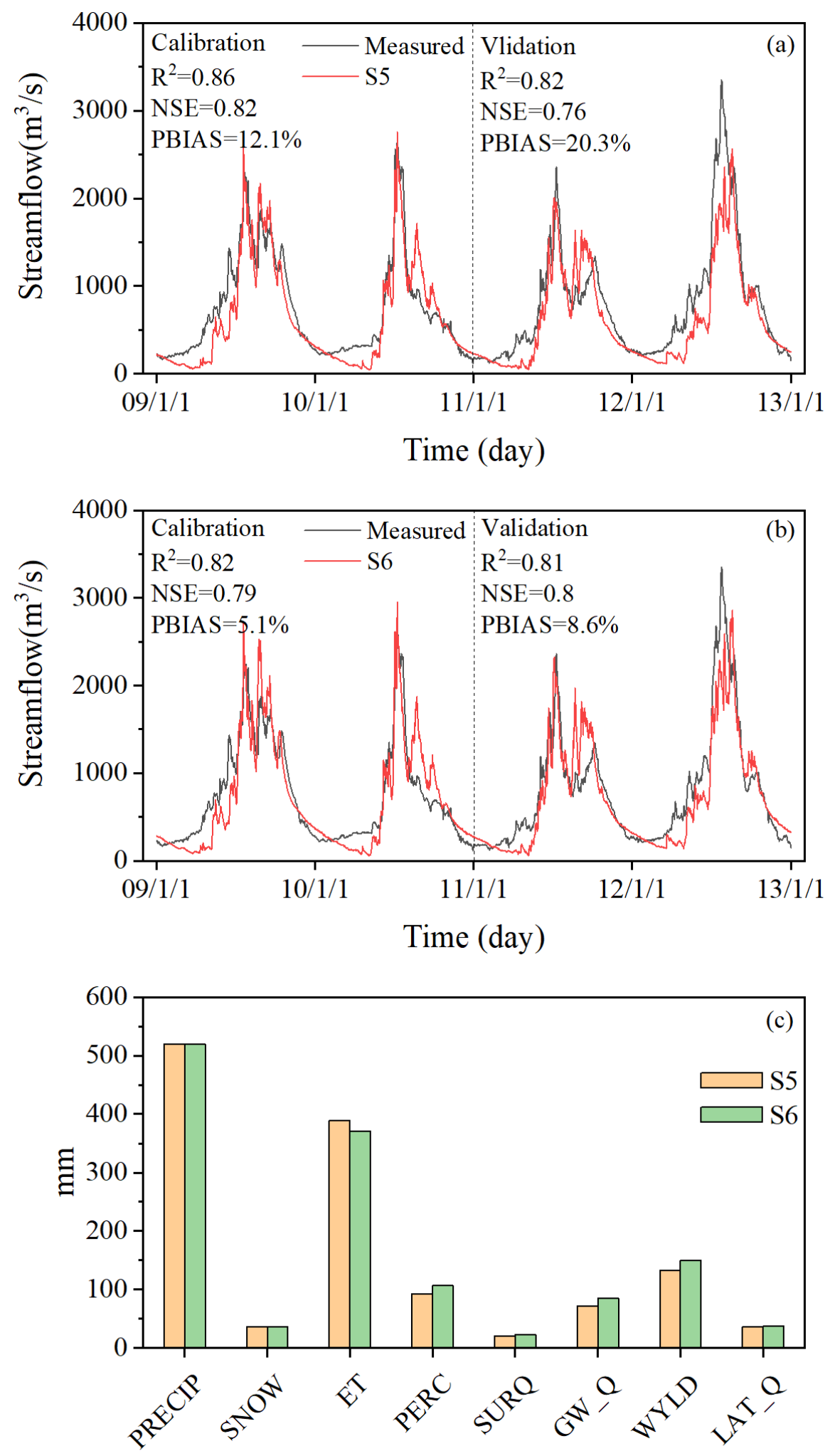

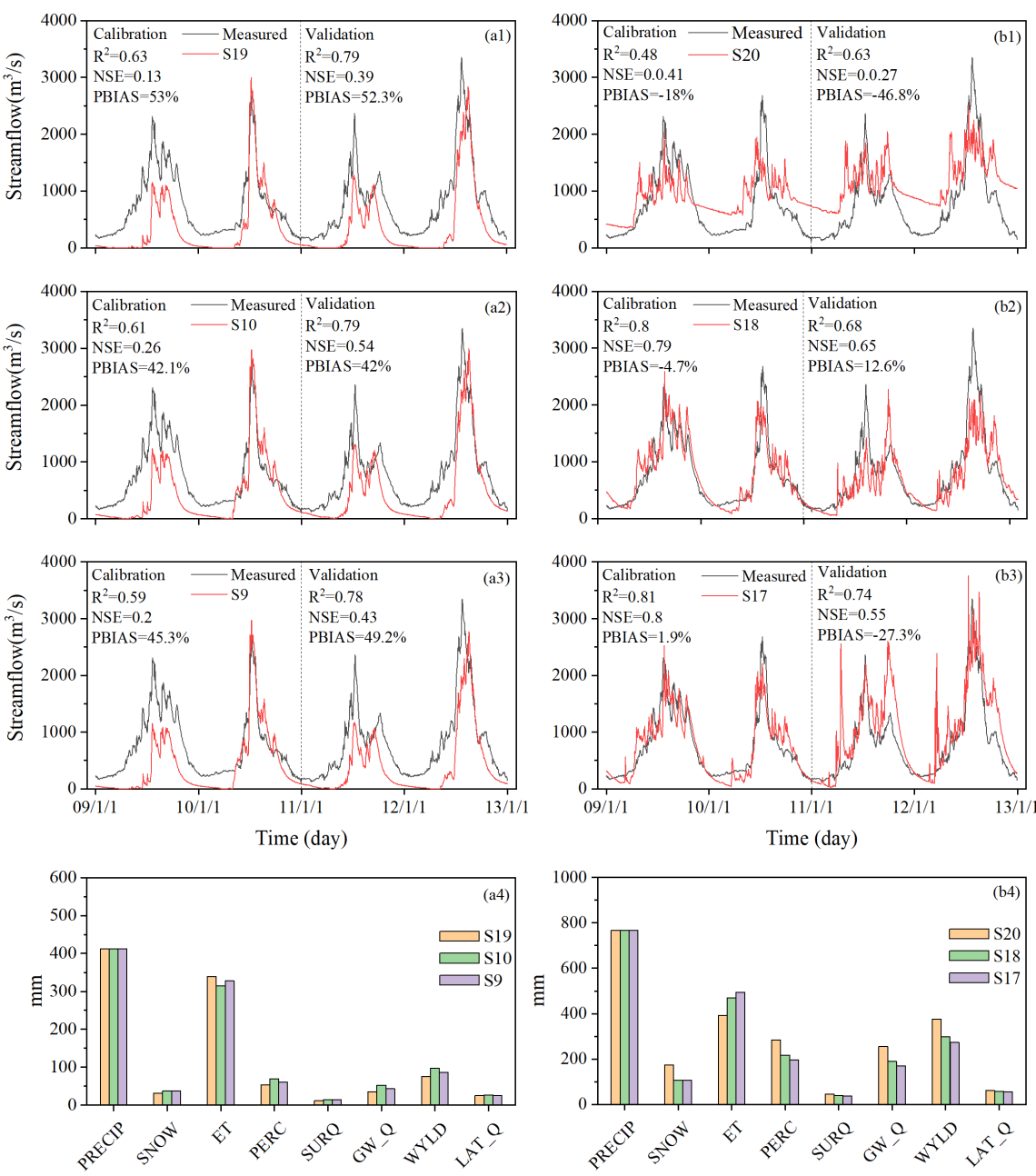

\section{Hosted file}

Table 1.docx available at https://authorea.com/users/360620/articles/482247-application-ofmeteorological-element-combination-driven-swat-model-based-on-meteorological-datasetsin-alpine-catchment-a-case-study-in-the-yellow-river-source-region-china

\section{Hosted file}

Table 2.docx available at https://authorea.com/users/360620/articles/482247-application-ofmeteorological-element-combination-driven-swat-model-based-on-meteorological-datasetsin-alpine-catchment-a-case-study-in-the-yellow-river-source-region-china

\section{Hosted file}

Table 3.docx available at https://authorea.com/users/360620/articles/482247-application-ofmeteorological-element-combination-driven-swat-model-based-on-meteorological-datasetsin-alpine-catchment-a-case-study-in-the-yellow-river-source-region-china

\section{Hosted file}

Table 4.docx available at https://authorea.com/users/360620/articles/482247-application-ofmeteorological-element-combination-driven-swat-model-based-on-meteorological-datasetsin-alpine-catchment-a-case-study-in-the-yellow-river-source-region-china 